\title{
O MOVIMENTO B CORP: SIGNIFICADOS, POTENCIALIDADES E DESAFIOS
}

\section{JULIANA RODRIGUES}

Mestra em Administração, Faculdade de Economia, Administração e Contabilidade - FEAC/USP-SP, Brasil. jurodrigues@usp.br

\section{GRAZIELLA MARIA COMINI}

Doutora em Administração, Faculdade de Economia e Administração - FEA/USP-SP, Brasil.

Docente livre-docência, Faculdade de Economia, Administração e Contabilidade - USP, FEAC/USP, Brasil

gcomini@usp.br

\section{Resumo}

As Empresas B (B Corps) vêm ganhando atenção na busca por articulações capazes de criar um elo entre o lucro e o interesse socioambiental. Este estudo qualitativo e interpretativo buscou compreender melhor este movimento empresarial, envolvendo um conjunto de 12 entrevistas para mapear seus significados a partir da percepção dos atores envolvidos, no Brasil e Estados Unidos. Percebe-se que a certificação pode ser considerada uma evolução dos mecanismos de prestação de contas ao incluir as etapas de confirmação, compromisso legal e identificação. 0 posicionamento ideológico e a atração de investidores de impacto são os principais motivadores para a certificação, percebida como uma forma de conferir legitimidade ao diferencial socioambiental das empresas. A percepção de ser uma marca pouco conhecida e de falta de benefícios práticos figura entre as principais fragilidades compensadas pelo fato de pertencer a uma comunidade que partilha dos mesmos valores e o potencial de networking e parcerias.

Palavras-chave: empresas B, B corp, organizações híbridas, negócios sociais, responsabilidade social. 


\title{
THE B CORP MOVEMENT: MEANINGS, POTENCIALITIES AND CHALLENGES
}

\begin{abstract}
$B$ Corps are gaining attention as they seek to produce articulations capable of creating a bond between profit and socio-environmental interest. This qualitative and interpretative study aimed to better understand this movement of business, by exploring a set of 12 interviews to map its meanings based on the perception of key stakeholders engaged in Brazil and in the United States. The certification can be considered an evolution of accountability mechanisms by including steps of confirmation, legal commitment and identification. Ideological positioning and attracting impact investments are key motivators for seeking the certification seen as a way of ensuring legitimacy to a socioenvironmental differential in business. The perception of a being an unknown brand and lack of practical benefits are important weaknesses compensated by belonging to a community that shares values and creates potential opportunities for networking and partnerships.
\end{abstract}

Keywords: B companies, B corps, hybrid organizations, social enterprises, social responsibility.

\section{EL MOVIMIENTO B: SIGNIFICADOS, POTENCIALIDADES Y DESAFIOS}

\begin{abstract}
Resumen
Las Empresas B (B Corps) han generado interés por la búsqueda de articulaciones capaces de crear un vínculo entre el lucro y el interés socioambiental. Este estudio tiene un enfoque cualitativo e interpretativo y busca comprender mejor este movimiento empresarial, basado en 12 entrevistas con el objetivo de mapear sus significado a partir de la percepción de actores involucrados, en Brasil y Estados Unidos. La certificación B puede ser considerada una evolución de los mecanismos de rendición de cuentas al incluir etapas de confirmación, compromiso legal e identificación. El posicionamiento ideológico y la atracción de inversionistas son factores de motivación para la certificación, percibida como una forma de generar legitimidad al diferencial socioambiental. La percepción de ser una marca poco conocida y la ausencia de beneficios prácticos son considerados debilidades compensadas por el hecho de pertenecer a una comunidad que comparte valores y por el potencial de networking y alianzas.
\end{abstract}

Palabras clave: empresas B, B corp, organizaciones hibridas, negócios sociales, responsabilidad social.

OS, Organizações e Sustentabilidade, 7(1), p. 47-70, Londrina, PR, jan./jun. 2019.

ISSN 2318-9223, http://www.uel.br/revistas/uel/index.php/ros/issue/view/1535/showToc 


\title{
INTRODUÇÃO
}

Ainda que o capitalismo tenha sido eficaz na criação de prosperidade e na melhoria do padrão de vida para muitos, sua forma atual passa por questionamentos e proposições de transformação (Sabeti, 2011). Como sistema socioeconômico vigente, busca-se inserir questões sociais e ambientais, baseados em novos valores e comportamentos (Yaziji, 2008). A orientação tradicional das empresas no sentido do desempenho financeiro, busca novas articulações capazes de criar elo entre lucro e interesse social (Porter \& Kramer, 2011).

Surgem, então, movimentos que buscam promover novos modelos organizacionais e desenvolver uma nova visão sobre o mercado e a lógica de resultados. Um exemplo é o movimento do Capitalismo Consciente, criado em 2008, liderado pelo empresário norte-americano John Mackey, cofundador da rede de supermercados WholeFoods, conhecido por sua proposta de valor voltada a temas de sustentabilidade, ao lado de Raj Sisodia, professor do Babson College. Outro grupo de executivos, o B Team, liderado por Richard Branson, do Virgin Group, foi criado, em 2013, com o mesmo propósito de alinhar interesses empresariais ao lema planeta-pessoas-lucro.

Dentre essas proposições, o movimento B Corp, ou das Empresas B, como é conhecido no Brasil, se destaca, tanto pelo início anterior, em 2007 nos Estados Unidos, quanto pelo crescimento e atratividade da mídia e no meio acadêmico. Busca oferecer um mecanismo de autoregulação e mensuração da performance socioambiental, tendo motes centrais "redefinir o conceito de sucesso nos negócios" e "usar a força dos negócios para o bem comum". Porém, apesar do crescente interesse na comunidade acadêmica e empresarial, citado inclusive como exemplo do fenômeno de hibridismo corporativo (Battilana, Lee, Walker, \& Dorsey, 2012; Haigh \& Hoffman, 2012), continua sendo um tópico pouco explorado. O presente trabalho pretende contribuir tanto para compreensão do movimento dessas empresas, quanto para a discussão do papel social das organizações e do hibridismo organizacional.

\section{REFERENCIAL TEÓRICO}

\begin{abstract}
Seja qual for o rótulo - capitalismo criativo, capitalismo filantrópico, nova economia, investimento de impacto, blended value, valor compartilhado - essas abordagens estão todas enraizadas na observação de que nenhuma reforma genuína pode acontecer enquanto as empresas voltadas para a maximização de lucros permanecerem como único motor de capitalismo. (Sabeti, 2011, p. 18, tradução nossa)
\end{abstract}

O emergente termo "organizações híbridas" vem ganhando cada vez mais espaço no cenário acadêmico. 0 conceito surge dentro de um contexto da evolução de abordagens que buscam inserir o valor social e ambiental na estratégia das organizações, como mostra a Figura 1. São organizações que combinam, de maneira desafiadora e sem precedentes, diferentes lógicas institucionais (Battilana \& Dorado, 2010; Battilana \& Lee, 2014; Battilana et al., 2012; Dufays \& Huybrechts, 2015; Lee \& Battilana, 2013; Schmitz, 2015). 
FIGURA 1 - EVOLUÇÃO DE CONCEITOS SOBRE O PAPEL SOCIAL DAS ORGANIZAÇÕES

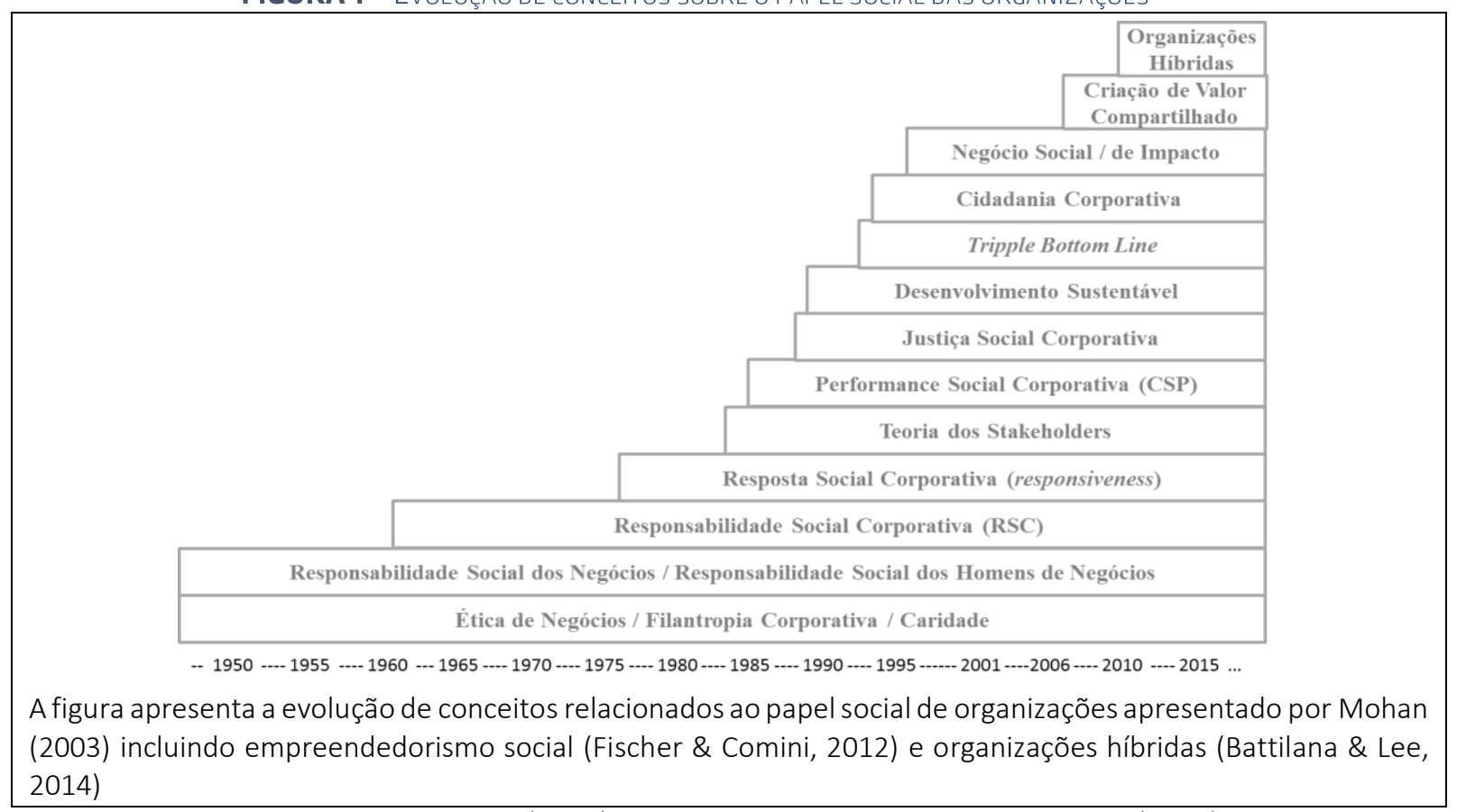

Fonte: adaptada de Mohan (2003) apud Bakker, Groenewegen, \& Den Hond (2005)

A lógica é precisamente promover uma atividade lucrativa que vai assegurar um propósito social mais amplo, mantendo essa dualidade de maneira interconectada e sinérgica (Haigh, Walker, Bacq, \& Kickul, 2015), em vez de apenas adicionar uma operação de geração de receita num modelo sem fins lucrativos ou um programa de caridade ao modelo de negócio lucrativo (Battilana et al., 2012). Um debate conceitual distingue duas perspectivas principais: se o hibridismo é um fenômeno regular e leva a diferentes graus de hibridismo, ou se refere-se a um tipo ideal com limites bem definidos (Schröer \& läger, 2015). Se visto como um movimento de hibridização (Battilana et al., 2012), as organizações podem ter diferentes graus de hibridismo (Schmitz, 2015), conforme a intenção de sua constituição: tradicionais empresas pró-lucro e puramente comerciais (empresarial) ou tradicionais organizações sem fins lucrativas e puramente filantrópicas (sociais). A organização totalmente híbrida estaria no centro pela geração de valor dual (Alter, 2007), sendo os negócios sociais um exemplo ideal de hibridismo (Battilana et al., 2012).

Diferentes perspectivas e abordagens que abordam o papel social das organizações, tais como responsabilidade social, sustentabilidade, valor compartilhado, entre outras, podem indicar, portanto, diferentes graus de hibridismo. Por meio de um levantamento, explicados no Quadro 1, no qual foram identificadas três perspectivas principais que trazem à tona o papel social das organizações - (1) Papel e responsabilidade de gestão; (2) Estratégia empresarial; (3) Novos modelos organizacionais -, é possível notar uma convergência com o espectro proposto por Alter (2007), apresentado na Figura 2, indicando estágios de hibridização organizacional. 
O Movimento B Corp: Significados, Potencialidades e Desafios

FIGURA 2 - RELAÇÃO ENTRE O ESPECTRO HÍBRIDO DE ORGANIZAÇÕES E AS FRENTES TEÓRICAS MAPEADAS

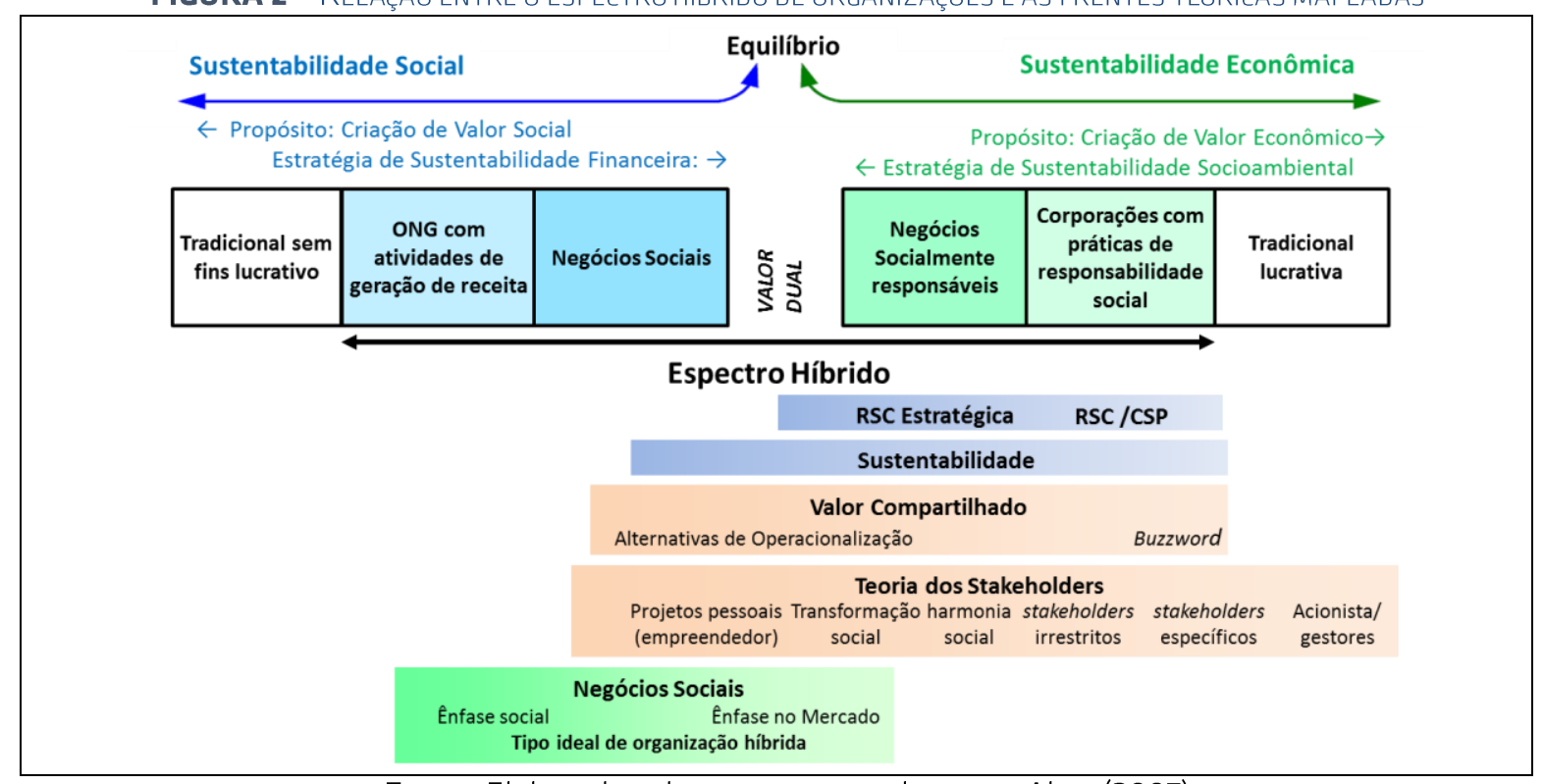

Fonte: Elaborada pelos autores, com base em Alter (2007)

OS, Organizações e Sustentabilidade, 7(1), p. 47-70, Londrina, PR, jan./jun. 2019.

ISSN 2318-9223, http://www.uel.br/revistas/uel/index.php/ros/issue/view/1535/showToc 


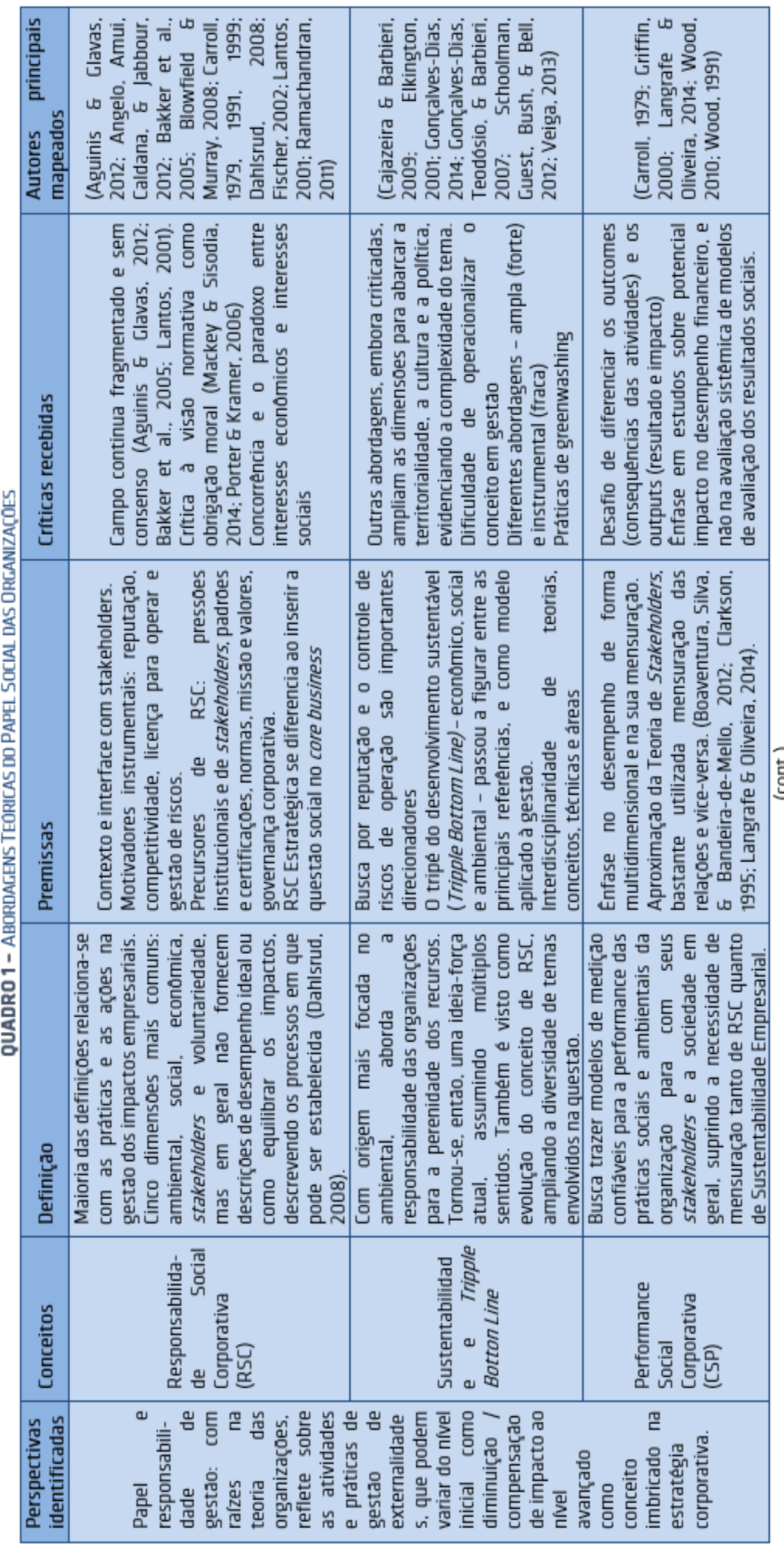

OS, Organizações e Sustentabilidade, 7(1), p. 47-70, Londrina, PR, jan./jun. 2019

ISSN 2318-9223, http://www.uel.br/revistas/uel/index.php/ros/issue/view/1535/showToc 


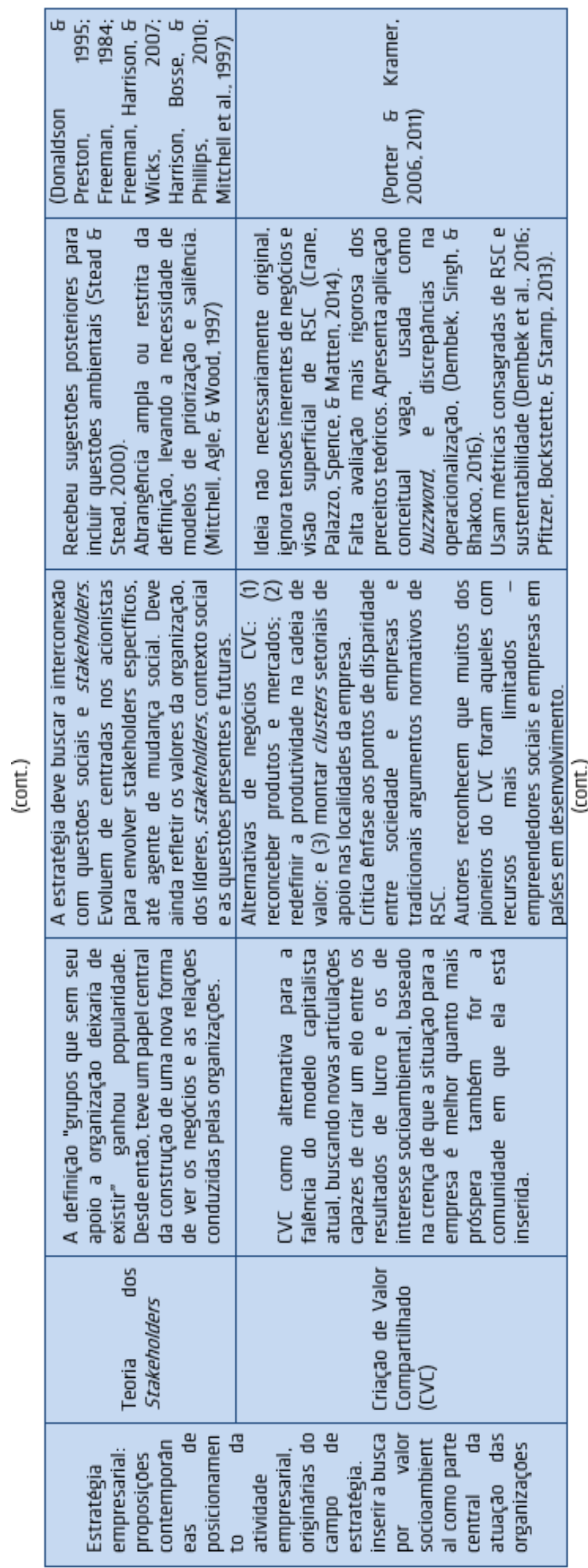

OS, Organizações e Sustentabilidade, 7(1), p. 47-70, Londrina, PR, jan./jun. 2019.

ISSN 2318-9223, http://www.uel.br/revistas/uel/index.php/ros/issue/view/1535/showToc 


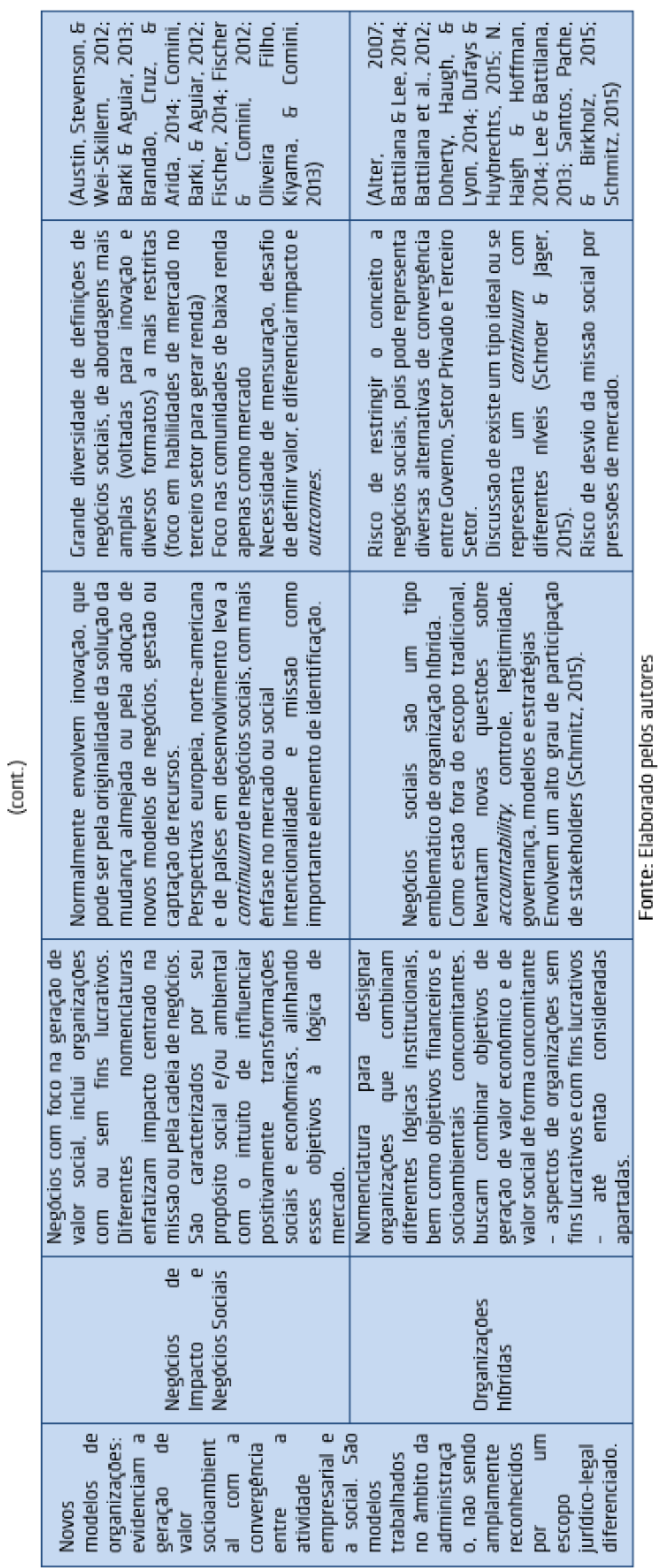

OS, Organizações e Sustentabilidade, 7(1), p. 47-70, Londrina, PR, jan./jun. 2019.

ISSN 2318-9223, http://www.uel.br/revistas/uel/index.php/ros/issue/view/1535/showToc 
Pesquisas sugerem que as organizações híbridas são frágeis, com risco de tensões internas, desvio da missão social pelas pressões de mercado e dificuldade para alcançar a sustentabilidade financeira (Battilana et al., 2012; Haigh et al., 2015; Kaiserfeld, 2013; Santos et al., 2015). Levantam novas questões sobre prestação de contas, governança, legitimidade, estratégias e modelos (Brandsen \& Karré, 2011; Schmitz, 2015). Battilana et al (2012) organizaram os desafios de gestão das organizações híbridas em quatro categorias principais: (1) estrutura legal; (2) alternativas de financiamento; (3) diferenciação entre cliente e beneficiário; e (4) cultura e desenvolvimento de talentos.

Em relação à estrutura legal, uma vez que as estruturas jurídicas tradicionais não se adaptam ao perfil misto, alguns empreendedores recorrem à complexa configuração de duas figuras jurídicas. Se constituída como uma organização com fins lucrativos, paga impostos sobre as receitas e não pode oferecer benefícios fiscais para doadores. Se configurada como uma organização sem fins lucrativos, não pode acessar seu capital próprio. Iniciativas, como a Benefit Corporation, buscam endereçar esse ponto, ao criarem uma nova constituição legal para configurar objetivos múltiplos (Battilana et al., 2012). Sobre as alternativas financeiras, a mudança no perfil de financiamento e investimento tornase outro desafio, pois os mecanismos ainda não são claros (Battilana et al., 2012). São poucas as linhas de investimento direcionadas aos negócios sociais, apesar do crescente interesse de investidores em buscar iniciativas com intenção de gerar impacto social (Izzo, 2013).

Já na diferenciação entre cliente e beneficiário, equilibrar esta distinção constitui um terceiro desafio e apoia o alinhamento estratégico (Battilana et al., 2012). Quando são diferentes, o modelo de negócio tende a ficar mais complexo e as tensões entre os objetivos mais latentes (Santos et al., 2015). A construção de uma cultura voltada tanto para o social quanto para o resultado financeiro é outro desafio, assim como recrutar, desenvolver e gerenciar pessoas que lidem com essa dualidade integrada (Battilana \& Lee, 2014; Battilana et al., 2012). A concepção do negócio e dos valores influenciam os modelos e práticas da organização, em consequência, sua identidade (Dufays \& Huybrechts, 2015) e o direcionamento da atuação também em momentos de crise (Schmitz, 2015).

\section{Apresentação do Objeto de Estudo: O Movimento B CoRP}

O Movimento B Corp nasceu nos Estados Unidos em 2007, com a constituição da organização sem fins lucrativos B Lab, com o objetivo de estimular empresas com foco na criação do valor compartilhado. Esteve fortemente ligada à proposta de viabilização de um novo modelo legal de organização, a Benefit Corporation, que inclui os interesses coletivos sob a lei tradicional de fins lucrativos (Reiser, 2010). Atua em três frentes principais (B-Lab, 2015; Wilburn \& Wilburn, 2014): 1. Legislação na criação de um novo formato de empresas com alto padrão de propósito, prestação de contas de transparência na geração de valor compartilhado (Benefit Corporations) nos Estados Unidos; 2. Certificação de empresas para estabelecer padrões comuns e distinguir empresas comprometidas com a responsabilidade socioambiental ( $B$ Corp, como é conhecida globalmente, ou "Empresa B" como é chamada no Brasil) e criar uma comunidade de "empresas do bem" - para receber a certificação a empresa deve alterar seus documentos legais, incluindo os interesses de empregados, fornecedores, clientes, comunidade e sociedade em geral (Reiser, 2010), sendo um dos pontos chave do movimento; 3. Investimento de Impacto, por meio de informações sobre as avaliações de impacto e performance socioambiental (B-Analytics) que estimulem um mercado de capitais apropriado, culminando no GIIRS (Global Impact Investing Rating System). 0 B-Impact Assessment $(B \mid A)$, desenvolvida pela B Lab, é uma ferramenta gratuita para avaliar a performance corporativa, social e ambiental das empresas, base tanto para a avaliação da certificação quanto para as informações para investimento de impacto - avalia dimensões relacionadas ao meio ambiente, comunidade, empregados, governança e clientes. 
0 movimento foi expandido globalmente para mais de 35 países. 0 Sistema B na América Latina, fundado em 2012, foi o primeiro parceiro internacional do B Lab, atuando inicialmente no Chile, Colômbia e Argentina. No Brasil, o lançamento oficial aconteceu em outubro de 2013, com especial foco na certificação, em parceria com empreendedores do CDI LAN, personalidades reconhecidas no campo de negócios sociais no País. Com a certificação da Natura, em 2014, foi possível notar que não se trata apenas de negócios sociais, mas um composto de organizações que adotam práticas de RSC, sustentabilidade e/ou valor compartilhado - construtos correlatos, porém, diferentes. Vale ressaltar que a certificação, foco do estudo, não é tida como uma classificação de negócios sociais, embora a lógica de sua comunicação transmita ideias similares.

\section{MÉTODO}

A presente pesquisa, de cunho interpretativista-construtivista, busca descrever os padrões de significados atribuídos pelos atores do próprio movimento (Berger \& Luckmann, 1976; Gephart, 1999; Pettigrew, 1985). Caracteriza-se como um estudo exploratório-descritivo, pois pretende conhecer mais sobre esse movimento emergente, seus significados e como ele pode representar uma proposta de mudança da visão de negócios, porém sem a pretensão de gerar generalizações ou comparações. Como objetivos específicos, buscou-se descrever os atores envolvidos; identificar os motivadores, as vantagens e desvantagens da certificação sob o ponto de vista da empresa certificada; e compreender a relação entre o movimento e as empresas certificadas.

Envolveu um conjunto de 12 entrevistas qualitativas com diferentes atores ligados ao movimento no Brasil, país da pesquisa, e Estados Unidos, país de origem do movimento. Semelhante estudo foi realizado na Austrália, envolvendo gestores de empresas certificadas no país (Stubbs, 2017). Ao incluir outros atores, este estudo busca ampliar a compreensão sobre os significados atribuídos ao movimento e à certificação. Buscou-se contrapor a percepção externa de stakeholders do movimento e a interna de representantes das organizações que representam o movimento: representantes do Sistema B (1) e do B-Lab (2); gestores de empresas brasileiras certificadas no Brasil (3) e nos Estados Unidos (3); gestores de empresa com potencial (prospects) de certificação no Brasil (2) e um acadêmico brasileiro que estuda o movimento (1).

O processo de codificação seguiu preceitos inspirados na proposta realizada por Strauss \& Corbin (2008) como técnicas de ordenação conceitual e metodológica, porém, sem a intenção de gerar teorias (Bandeira-de-Mello \& Cunha, 2003). A fim de manter a abertura e atenção à compreensão dos principais fatores que delineiam o movimento per se, foram produzidos inicialmente mais de 250 códigos na primeira etapa de microanálise dos dados. Estes códigos foram reduzidos, renomeados e agrupados em categorias mais relevantes (Strauss \& Corbin, 2008). As entrevistas foram novamente codificadas, utilizando o software NVivo, a fim de integrar as relações entre os dados obtidos na primeira fase de codificação aberta e produzir uma visão processual dos atores envolvidos no movimento (Langley, 1999; Strauss \& Corbin, 2008).

\section{APRESENTAÇÃO DOS RESULTADOS}

\footnotetext{
“Eu tenho a impressão de que a B Corp é mais do que uma certificação, é um movimento que vem com uma tentativa de mudança de paradigma, da forma de produzir e de trabalhar em termos de empresas e organização no mundo atual." Empreendedor prospect brasileiro (E01)
}

O movimento como um todo pode ser retratado conforme dois eixos principais: o propósito e a certificação, embora sejam entrelaçados e sobrepostos. Enquanto o propósito é percebido de forma abrangente, com forte tom ideológico na busca por uma "mudança de paradigma" (in vivo) nos negócios, a certificação é uma "ferramenta". Conforme representante do Sistema B (E04), "a certificação não é um fim, mas um meio". O movimento é impulsionado pela "tendência de [as

OS, Organizações e Sustentabilidade, 7(1), p. 47-70, Londrina, PR, jan./jun. 2019. 
empresas] tornarem-se negócios cada vez mais sociais" (certificada Brasil E03) e "vem na esteira de um movimento histórico de repensar o uso dos recursos" (prospect E01). Termos como "sociedade sustentável", "desenvolvimento sustentável", "economia verde" e "valor compartilhado" surgiram nas entrevistas para demonstrar a tendência, não apenas de mercado, mas da sociedade. Busca se diferenciar por perseguir um "objetivo utópico" (in vivo) de mudar o jeito de se fazer negócios.

\title{
O PROPÓSITO E OS ATORES dO MOVIMENTO B CORP
}

\begin{abstract}
"Um movimento de pessoas que usam a força do seu negócio e criam uma comunidade comprometida em promover ações para fazer uma mudança sistêmica, a princípio em seu próprio negócio, mas que geram impacto no sistema." Empreendedor certificado Brasil (E05)
\end{abstract}

Um movimento de pessoas - empreendedores, investidores e personalidades - orientadas por uma nova cultura de negócios e um forte posicionamento ideológico de que as empresas podem e devem ser promotoras de transformações positivas e bem-estar na sociedade: essa é uma das principais definições sobre o movimento obtidas pelas entrevistas. Pessoas que "colocam seus propósitos de vida e suas ideologias na sua empresa", como avalia um representante do Sistema B (E04), tendo a essência socioambiental e os valores pessoais como base de sustentação. "Cultura é o que coloca o movimento como um todo no radar", afirmou um representante do B-Lab (E12).

Marcado como um movimento pequeno e incipiente, ainda é pouco conhecido para a maior parte da população e até mesmo para o público de negócios. Ao mesmo tempo em que há o risco de ser tido como um movimento de nicho, para as pessoas "já convertidas", reconhece-se nele um forte poder de mobilização e engajamento, com potencial para um crescimento expressivo.

\footnotetext{
“Esse pensar criticamente o movimento é importante. São pessoas muito boas que estão entrando naturalmente e já têm esse olhar. Mas, eu brinco sempre que são os convertidos. (...) E a gente precisa tentar de algum jeito trabalhar com os não convertidos. Esse é um desafio ainda maior e mais urgente." Empreendedor prospect Brasil (E01)
}

Traduzir e materializar o que é este "novo paradigma de negócios" constitui, então, um dos principais desafios. O caráter ideológico e abstrato da afirmação "usar a força de negócios para o bem comum" dificulta a concretização do que representa esta proposta. Sabe-se que busca inserir o papel social no centro de atuação empresarial, mas o que isso significa e como isto é feito torna-se abstrato e confuso, dado que pode tanto ser as práticas de gestão quanto o objeto central do negócio.

\begin{abstract}
"Nós precisamos educar sobre quais são as práticas negativas ainda praticadas como norma, como é feito com o certificado de orgânicos (...) Orgânico é relativamente fácil de explicar ... Comércio justo começa a ficar um pouco mais complicado porque precisa contar uma história. Já a B Corp parece ser ainda mais desafiador principalmente porque comunicamos duas frentes [legislação e certificação] de uma vez. (...) A gente focou nossos esforços em explicar a B Corp e o fato de que a empresa como um todo é certificada." Representante B Lab (E11)
\end{abstract}

Explicar o movimento por meio das empresas que fazem parte dele torna-se um dos principais mecanismos para definir sua identidade. É bastante comum citarem as empresas certificadas para explicar o perfil e objetivos do movimento e da certificação, uma das formas de tangibilizar seu propósito abstrato. Ao mesmo tempo, está sujeito a diversas interpretações e dificultando a construção de uma identidade única.

\footnotetext{
"Estou utilizando a lente da Raízes, da Asta, do Criando, que são certificadas, que tem algumas coisas em comum" Empreendedor prospect Brasil (E01)
}

Vale observar as nomeações aplicadas ao movimento, dado o excesso de expressões envolvendo a letra B, pois muitas vezes os nomes e conceitos se sobrepõem, dificultando a consolidação de sua imagem. Há grande confusão sobre a diferença entre as Benefit Corporationse a B Corp, mesmo nos Estados Unidos, aumentando o desentendimento sobre as iniciativas.

OS, Organizações e Sustentabilidade, 7(1), p. 47-70, Londrina, PR, jan./jun. 2019. 
“Por um lado é 'naming', certo? Nós atribuímos nomes às coisas de uma forma muito confusa. (...) Então eu acho que em parte porque [o tema] é complicado e em parte porque nomeamos as coisas quase exatamente da mesma maneira." Representante B Lab (E11)

Ao buscar o arrojado objetivo de mudar o paradigma de negócios, o movimento procura articular o relacionamento entre diferentes atores, sendo possivel classificá-los como stakeholders primários e secundários (Freeman et al., 2007). Os primários são aqueles diretamente envolvidos no movimento - B Lab, Sistema B e empresas certificadas - e os influenciadores determinantes para impulsionar a certificação, como o grupo de investidores de impacto, usuários diretos do sistema de informação (GIIRS). Especialmente no Brasil, um dos principais motivos para empresas se certificarem foi a exigência de mensuração para o investidor interessado. Já aqueles que estão envolvidos nos objetivos do movimento no nivel de influência foram considerados stakeholders secundários. 0 governo aparece como um influenciador direto, por conta da frente de legislação e políticas públicas, bem como as possíveis empresas a serem certificadas que possibilitariam ampliar o movimento. Academia e imprensa apresentam influência indireta, pois são importantes na disseminação, porém não estão diretamente ligadas à ação de certificação.

\section{A Certificação B Corp como Processo}

A visão da certificação como processo, sob a perspectiva da empresa, se dá em três momentos, como mostra a Figura 3. O primeiro momento é a atração e a motivação para certificação, quando o empreendedor toma conhecimento e avalia sua relevância e sua aderência. O discurso oficial do BLab e Sistema B sobre os motivos para uma empresa se certificar trabalha com uma ampla gama de razões. No site, por exemplo, é apresentado um grupo de oito benefícios (Sistema B, 2014), porém não dão a dimensão de quais são os aspectos centrais que impulsionam a decisão pela certificação.

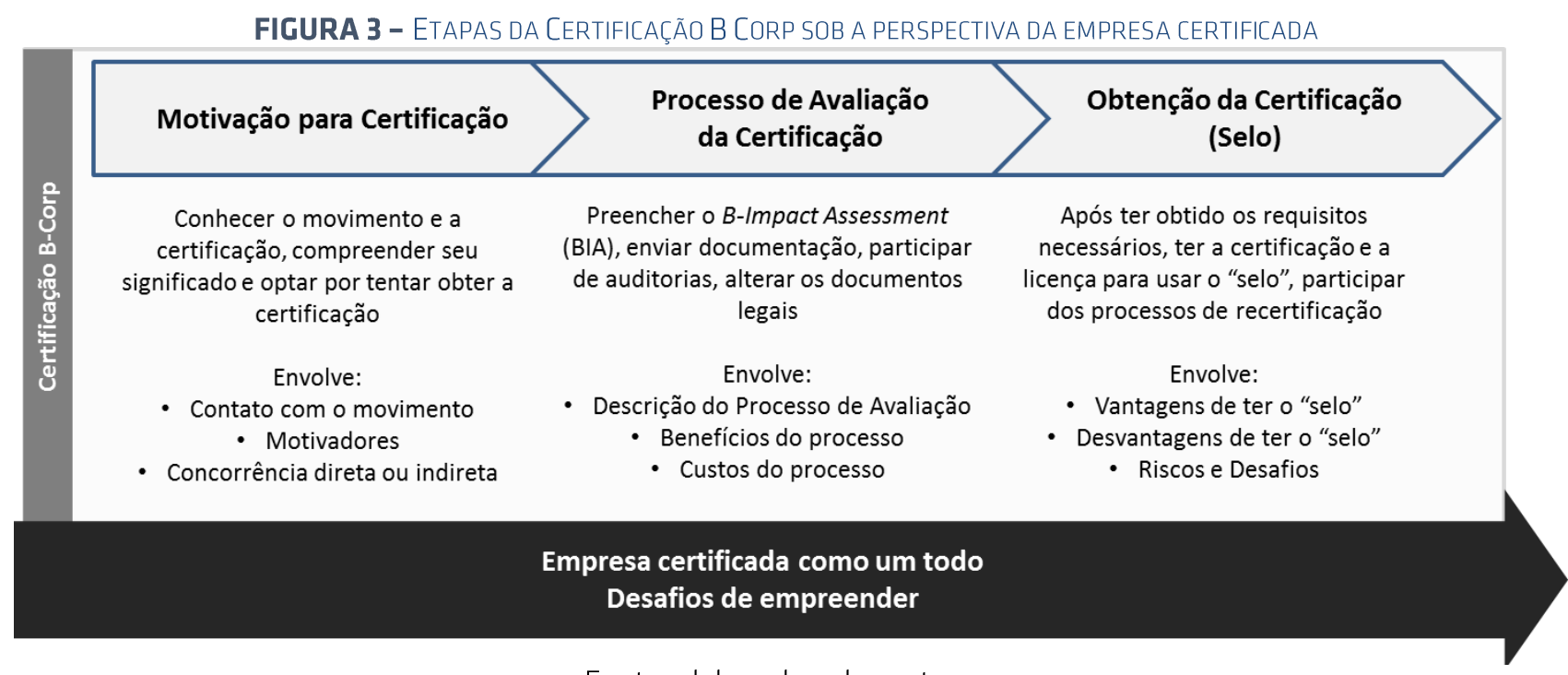

Fonte: elaborada pelos autores

Nesse sentido, ainda que nas entrevistas tenham sido mencionados diferentes motivos, nota-se uma ênfase em aspectos ideológicos, somado, especialmente no Brasil, à questão pragmática de atração de investimento de impacto. Nos Estados Unidos, foi mencionada a manutenção da missão e da cultura. Nesse sentido, a certificação B é única, com a vantagem expressiva de já estar conectada a diversos grupos de investimento de impacto pelo GIIRS.

"A gente estava em processo de criar a empresa social e captou com um fundo de investimento de impacto [nome excluído] para criar a empresa social. E uma grande dúvida que eu tinha pessoalmente como empreendedor social era como medir intencionalidade (...) Eu encontrei uma ferramenta chamada GIIRS e na época o fundo já estava passando por um processo de certificação para virar um fundo GIIRS." Empreendedor certificado Brasil E05

OS, Organizações e Sustentabilidade, 7(1), p. 47-70, Londrina, PR, jan./jun. 2019.

ISSN 2318-9223, http://www.uel.br/revistas/uel/index.php/ros/issue/view/1535/showToc 
O principal desmotivador é a concorrência de recursos frente aos desafios de empreender, como busca por financiamento, desenvolvimento de capacidade de gestão, entre outras atividades inerentes ao ambiente de negócios. Essa necessidade e concorrência são ainda mais sentidas por pequenas empresas, nas quais acesso a recursos torna-se ainda mais crítico e difícil.

\footnotetext{
“Talvez dependendo do momento da organização isso [redes de networking de conteúdo] seja muito mais útil, muito mais relevante, quando a empresa está precisando muito mais de capacity building, do que de chancela." Empreendedor prospect (E01)
}

Não é percebido nenhum concorrente direto da certificação B, uma vez que ela aborda a empresa como um todo, suas práticas de gestão e relacionamentos multistakeholders. No entanto, ela concorre com diversos novos selos atrelados a uma nova consciência de negócios, como: Orgânicos, Fair Trade, Certified Humane, ISO e FSC. A certificação B também concorre indiretamente com outros mecanismos de prestações de contas e premiações que se prestam a fins semelhantes, tais como: Melhores Empresas para Trabalhar, Indicadores Ethos e GRI.

O segundo momento começa após a decisão da empresa por buscar o selo, dando início ao processo de certificação. 0 questionário rico e abrangente é apontado como uma das forças, pois ajuda a "medir onde é que (as empresas) estão nessa caminhada de redefiniçao do papel das empresas e de sucesso de negócios", como disse o empreendedor certificado brasileiro (E05).

"O aspecto mais legal do B-Impact Assessment (BIA) é que cada vez mais eu escuto CEOs

se referirem a ela como o 'guarde reio' para negócios do bem." Representante B-Lab (E12)

O processo de avaliação também tem custos, especialmente de horas dedicadas. Os custos financeiros também podem ser considerados "significativos dependendo do porte da empresa" (Empreendedor certificado - E02). No entanto, não parecem exercer forte influência negativa após a decisão por obter o selo, pois são levados em conta no momento anterior. O processo é eletrônico, facilitando a condução, mas também representa um risco de credibilidade.

\footnotetext{
“Tem uma etapa do processo que as pessoas poderiam vir in loco para avaliar realmente (...). Por exemplo, auditorias ISO são um mega esforço, precisa ter as coisas na mão, não é só enviar uma evidência online. É diferente o auditor vir, e falar 'me traz isso' ou 'deixa eu conversar com seu funcionário'. A história é outra." Empreendedor certificado Brasil (E02)
}

Após obter a certificação, a empresa ganha o direito de usá-lo e passa a constar na comunidade de empresas B, o que foi denominado como obtenção do "selo", constituindo o terceiro momento. "O selo acaba sendo um comprovante da atuação da empresa", como ressaltou o empreendedor prospect (E07).

\footnotetext{
"Mesmo sem saber exatamente, sem conhecer o sistema B, só o fato de ser um certificado internacional, reconhecido, com pessoas sérias por trás, já traz credibilidade, se a pessoa quiser saber mais ela pode procurar o site (...) Você fala que é um certificado internacional e tem mil empresas pelo mundo, é um negócio mais sério." Empreendedor certificado Brasil (E03)
}

Esse momento também reforça a caracterização do movimento, uma vez que é, em grande parte, delineado com base na imagem das certificadas. São ainda percebidas vantagens e desvantagens, resumidas na Figura 4. 
FIGURA 4 - MAPA DE VANTAGENS E DESVANTAGENS DA CERTIFICAÇÃO B CORP APÓS OBTENÇÃO DO SELO

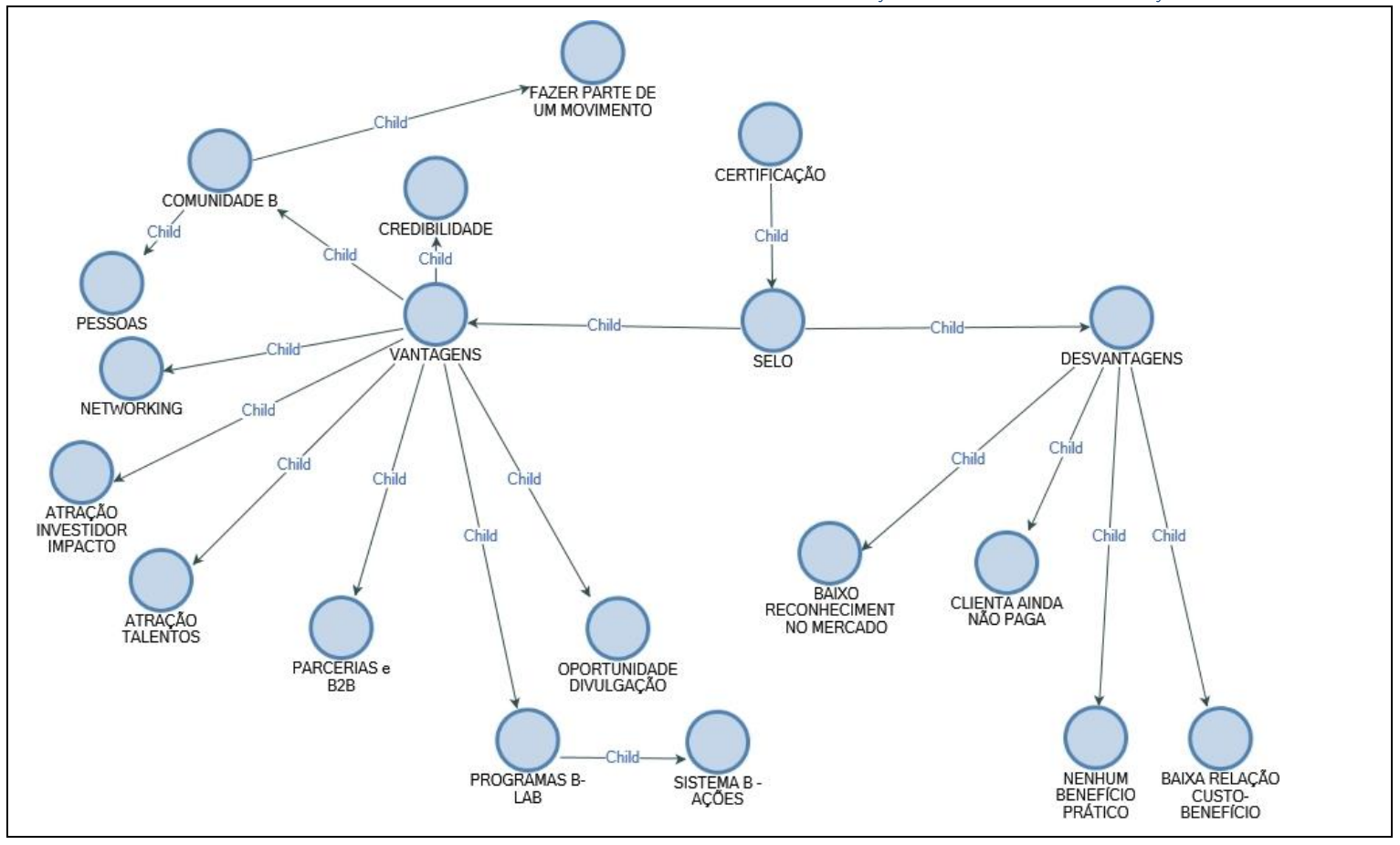

Fonte: elaborada pelos autores com base na análise de dados NVivo

As vantagens mais expressivas reconhecidas pelos entrevistados derivam do posicionamento ideológico que motiva a certificação, o que the confere um diferencial e uma maior credibilidade de seu discurso. Em um segundo nível, gera uma rede de relacionamento (networking) com empresas e líderes que partilham dos mesmos valores, criando um senso de comunidade. Como apareceu em pesquisa similar na Austrália, a sensação é de fazer parte de um clube (Stubbs, 2017).

No entanto, a proposta ainda não é expressiva em relação aos clientes e consumidores. Como disse o empreendedor brasileiro certificado (EO3), "os clientes, em geral, valorizam, mas dificilmente pagam por isso". A ausência de um benefício prático leva a uma percepção de baixa relação custobenefício da certificação, compensada apenas pela força do posicionamento ideológico. "Hoje o valor percebido é muito pequeno" (Empreendedor certificado Brasil E03). O baixo conhecimento (awareness) da certificação interfere na pouca atratividade. "Precisa reforçar sua imagem e mostrar que é uma coisa mais especial", afirma o empreendedor prospect (E01). A construção da marca seria uma vantagem prática capaz de atrair mais organizações.

Dessa forma, gerar visibilidade e reconhecimento do selo é um dos principais desafios, pois poderia também reverter cada vez mais vantagens para as organizações certificadas. Para gerar mais reconhecimento, os atores envolvidos entendem que é importante influenciar mudanças nas empresas ainda "não convertidas" e, assim, "aumentar a massa crítica" (in vivo) do movimento.

\footnotetext{
"Eu acho que hoje tem uma massa crítica pequena, precisa atingir um número de empresas. (...) como é que você vai fazer um programa de financiamento de empresas B. quantas precisam disso? Duas, três. Massa crítica, que massa você tem para falar de um acordo com um banco, vai, uma linha de crédito para empresas B." Empreendedor certificado Brasil (E03).
}

A lógica subjacente é de que quanto maior a comunidade de Empresas B, maior representatividade do movimento e, consequentemente, maior o poder de argumentação e barganha por novos benefícios, por exemplo, opções de preferência de financiamento e de compra. Porém, "aumentar massa crítica" traz outros dilemas, pois há o risco de descaracterizar o que representa a certificação 
ao aceitar cada vez mais empresas de diferentes perfis. Há ainda os riscos inerentes à sustentação financeira e rentabilidade que podem desvirtuar seu objetivo.

\begin{abstract}
“Não gostaria de fazer parte de um grupo se eu começar a identificar que tem organizações que têm visões antagônicas de mundo, aí é um problema grave. E tem uma pressão econômica para a certificação acontecer, pois é entrada de recurso." Empreendedor prospect (E07)
\end{abstract}

Esse dilema é reforçado pela dificuldade de explicar claramente qual o "tema" da certificação, para defini-lo, os entrevistados utilizaram diferentes termos e explicações. Muitas vezes tratados como sinônimos, afirmou-se que o BIA refere-se a: avaliação das práticas gerenciais, nível das práticas de responsabilidade social, requisitos de performance, mensuração da performance socioambiental, mensuração do impacto e garantia de que a sustentabilidade está no centro da estratégia de forma transversal. São elementos relacionados entre si, mas que dificultam o reconhecimento exato da definição de impacto utilizada. O posicionamento oficial do Sistema B é de que a certificação pode ser concedida para qualquer empresa com fins lucrativos, incluindo negócios sociais, mas que tenha práticas de gestão que permitam uma melhor performance socioambiental ou então a geração intencional de impacto positivo.

\begin{abstract}
"O conceito de Empresa B é muito mais amplo porque ele pode ser uma empresa de vários movimentos que estão acontecendo no mundo. Pode ser um negócio social, pode ser uma empresa que atua com o valor compartilhado (...), pode ser uma empresa que faz parte do movimento do Capitalismo Consciente, pode ser uma empresa do movimento do B Team do Manson... a questão é: toda Empresa B tem que ser uma empresa, em primeiro lugar, tem que ser lucrativa, se ela vai doar o lucro, se ela vai reinvestir o lucro, ou se ela não vai distribuir o lucro é uma questão de governança interna dela. Então o conceito de Empresa B é um pouco mais amplo do que o conceito de negócios sociais" Empreendedor certificado Brasil (E05)
\end{abstract}

Porém, ao certificar empresas não orientadas à missão social, mas com excelentes práticas de gestão e requisitos de performance, não se diferencia dos movimentos de responsabilidade social, sustentabilidade ou valor compartilhado já existentes. A diferenciação entre ser um negócio de impacto ou uma empresa com excelentes práticas de gestão acontece de maneira sutil na certificação, por meio das notas atribuídas às dimensões do BIA. Segundo uma representante do B Lab, o "BIA prefere e dá mais pontos às organizações que têm modelo de negócio de impacto no seu núcleo, ou seja, quanto mais central, maior a pontuação".

\footnotetext{
“A melhor Empresa B do mundo não é perfeita. A ideia da ferramenta é ajudar a empresa a criar um plano de desenvolvimento contínuo. Eu não posso afirmar que empresas que tenham uma estratégia de responsabilidade social um pouco mais sofisticada, mas que ainda não sejam uma Empresa B na essência, não passariam pelo BIA. Talvez passariam (...) mas na evolução da ferramenta, dificilmente se sustentaria." Empreendedor certificado Brasil (E05)
}

Como resultado, há uma enorme heterogeneidade no grupo de empresas certificadas, o que dificulta a caracterização e singularidade do movimento e, até mesmo, a identificação de algumas delas com a comunidade. São empresas de diferentes setores, atividade-fim, modelos e estrutura de capital, e porte, embora a maioria seja de pequeno porte. Além disso, são bastante heterogêneas no quanto incorporam seu papel social, incluindo alguns modelos ideais de hibridismo, mas também abordagens de responsabilidade social e sustentabilidade. Este parece ser outro ponto bastante sensivel para a construção de um posicionamento único e forte pelo movimento.

\footnotetext{
"Às vezes você conversa com alguém que é de um segmento tão diferente, mas tão diferente, que dificilmente a gente se identifica." Empreendedor certificado Brasil (E02)

“É difícil em comparação com outros negócios, por exemplo, nós ainda somos muito pequenos e às vezes nossas notas não refletem quem nós somos por conta do nosso tamanho" Empreendedor certificado EUA (E09)
}

OS, Organizações e Sustentabilidade, 7(1), p. 47-70, Londrina, PR, jan./jun. 2019. 
Uma das sugestões para diferenciar as empresas certificadas que atuam diretamente na geração de valor socioambiental em modelos orientados à missão social tem como referência os típicos níveis de alcance presentes em outras certificações. Esta subdivisão também é vista por outros pesquisadores como uma das possibilidades de evolução das empresas B na constituição de um novo modelo organizacional (Bilgili, Worrell, Ellstrand, \& Johnson, 2015).

\begin{abstract}
"Muitas vezes têm certificados, por exemplo, que vão ao nível 1,2 e 3. Não ganha o certificado do Sistema B, você ganha o Sistema B1. Tem muito a andar para frente. Eu não sei se o sistema B tem isso e como é esse formato. Eu gostaria que tivesse, né, para ter uma provocação cada vez maior, aí as empresas começam a se movimentar. (...) não dá para botar todo mundo no mesmo cesto (...) Mas cuidado, já estamos trabalhando num nicho, eu não sei se sou a favor de nichar ainda mais, eu acho que tudo é uma coisa só." Empreendedor prospect (E01)
\end{abstract}

Como propósito, o movimento quer "usar a força dos negócios para problemas sociais e ambientais" (B-Lab, 2015, tradução nossa). Como certificação, busca garantir que as certificadas atendem "padrões rigorosos de desempenho social e ambiental, responsabilidade e transparência"(B-Lab, 2015, tradução nossa). Ao mesmo tempo em que se complementam, também se confundem, pois levam a duas mensagens sujeitas a interpretações distintas: Empresas B são empresas que atuam com foco em problemas sociais e/ou ambientais e Empresas B são empresas que se comprometem com padrões de responsabilidade socioambiental.

\title{
DISCUSSÃO DOSRESULTADOS
}

Para promover um novo modelo e conceito de sucesso nos negócios, o caminho planejado pelo movimento é: (1) mensurar a performance socioambiental das empresas; (2) reconhecer e identificar as empresas com performance positiva; (3) diferenciá-las das demais pelo "selo"; e (4) ampliar o movimento. Nesse sentido, a certificação se torna o principal ponto de convergência entre o movimento e as empresas, pois atende as mesmas necessidades da empresa certificada de ter sua performance socioambiental (1) mensurada, (2) reconhecida, (3) diferenciada e (4) ampliando sua rede de relacionamentos, como mostra a Figura 5. A etapa "mensurar" envolve o processo de avaliação (BIA). A certificação já concedida, o "selo", ajuda a reconhecer e diferenciar as empresas, dando visibilidade e legitimidade ao modelo.

É interessante ainda notar que as frentes de atuação do movimento, com especial foco na certificação, apoiam as organizações híbridas nos desafios mapeados por Battilana et al (2012), isto é, os desafios de: (1) estrutura legal; (2) alternativas de financiamento; (3) diferenciação entre cliente e beneficiário; e (4) cultura e desenvolvimento de talentos.

A certificação confirma que o compromisso socioambiental está embutido no centro da missão e estratégia por meio do aspecto principalmente simbólico da alteração dos documentos legais, ainda que isso não interfira na orientação à missão no modelo de negócio (Alter, 2006, 2007). Não representa uma nova composição jurídica de organização, como é a constituição legal da Benefit Corporation, utilizada como exemplo de organização híbrida por Battilana et al. (2012). No entanto, essa alteração no estatuto é uma forma de reafirmar a missão e buscar protegê-la, contornando o risco típico de organizações híbridas em relação ao desvio da missão (Battilana et al., 2012; Ebrahim, Battilana, \& Mair, 2014; Nardia Haigh et al., 2015; Kaiserfeld, 2013; Santos et al., 2015). Vale destacar que a confusão entre as frentes Benefit Corporation como estrutura legal e a B Corp como certificação agrava o equivocado entendimento de que as empresas certificadas são organizações híbridas no formato ideal de negócio social.

OS, Organizações e Sustentabilidade, 7(1), p. 47-70, Londrina, PR, jan./jun. 2019. 
FIGURA 5 - PONTOS DE CONVERGÊNCIA DO MOVIMENTO BCORP E AS EMPRESAS B

\begin{tabular}{|c|c|c|}
\hline $\begin{array}{l}\text { Propósito Movimento B Corp: } \\
\text { Mudança de Paradigma (in vivo) }\end{array}$ & $\begin{array}{c}\text { PERFORMANCE E IMPACTO } \\
\text { SOCIOAMBIENTAL }\end{array}$ & $\begin{array}{l}\text { Empresas B: (in vivo) } \\
\text { Core-estratégico: socioambiental }\end{array}$ \\
\hline Legitimidade e Tangibilização do Movimento & CERTIFICACCÃO & $\begin{array}{l}\text { Legitimidade e Tangibilização do diferencial } \\
\text { socioambiental }\end{array}$ \\
\hline $\begin{array}{l}\text { MOVIMENTO DE PESSOAS: } \\
\text { - Empreendedores Sociais e Expoentes } \\
\text { Sustentabilidade } \\
\text { - Novo Perfil de Investidor }\end{array}$ & $\begin{array}{l}\text { IMPULSIONADOR: } \\
\text { NETWORKING E REPUTAÇÃO } \\
\text { PESSOAL }\end{array}$ & $\begin{array}{r}\text { MOTIVADORES: } \\
\text { - Posicionamento Ideológico - Fundador/Líder } \\
\text { - Atração de Investimento de Impacto }\end{array}$ \\
\hline $\begin{array}{l}\text { B-Impact Assessment (BIA) } \\
\text { - Adaptabilidade por modelo de negócio } \\
\text { - Evolução contínua dos critérios } \\
\text { Força: certificação independente, alteração dos } \\
\text { documentos legais } \\
\text { Fragilidade: ausência de auditoria presencial }\end{array}$ & $\begin{array}{l}\text { MENSURAR: } \\
\text { Processo de avaliação }\end{array}$ & $\begin{array}{r}\text { - Credibilidade da proposta de valor } \\
\text { - "Comprovação" de impacto socioambiental } \\
\text { Força (Benefícios): diagnóstico, documentação e } \\
\text { melhorias } \\
\text { Fragilidade (Custos): custos financeiros e } \\
\text { humanos / concorrência de recursos }\end{array}$ \\
\hline $\begin{array}{l}\text { FOCO: Visibilidade para novo modelo de negócio } \\
\text { Força: Sem concorrente direto. Movimento } \\
\text { crescente. Proposta atraente } \\
\text { Fragilidade: Baixo reconhecimento, Benefícios e } \\
\text { programas ainda não implementados no Brasil }\end{array}$ & $\frac{\text { RECONHECER E DIFERENCIAR: }}{\text { Selo }}$ & $\begin{array}{r}\text { FOCO: Legitimidade do posicionamento } \\
\text { Vantagens: comunidade B, parcerias, relações } \\
\text { B2B, atração de investimento } \\
\text { Desvantagens: não atrai clientes, pouco } \\
\text { benefício prático, baixo reconhecimento }\end{array}$ \\
\hline $\begin{array}{l}\text { - Aumentar representatividade } \\
\text { - Aumentar poder de barganha na criação de benefícios } \\
\text { Força: Certificação Natura e outras grandes (visibilidade) } \\
\text { Fragilidade : Identidade dispersa, definição confusa de } \\
\text { impacto }\end{array}$ & $\begin{array}{c}\text { AMPLIAR: } \\
\text { Foco: Aumentar massa crítica } \\
\text { Objetivo utópico: “Todas as empresas } \\
\text { serão B" }\end{array}$ & $\begin{array}{r}\text { - Autoregulação } \\
\text { - Aumentar reconhecimento do selo } \\
\text { Força: Setor de Negócios Sociais } \\
\text { Fragilidade: Incipiente, desalinhamento }\end{array}$ \\
\hline
\end{tabular}

Fonte: elaborada pelos autores

A conexão promovida pelo B-Lab entre investidores de impacto e empreendedores é um exemplo de promoção de acesso ao capital e alternativas de financiamento, e evidencia a certificação como ferramenta de gestão além do posicionamento ideológico. Já no desafio de construção de cultura e desenvolvimento de talentos, a atração de empregados engajados e a definição de políticas e processos estimulada pelo BIA, ajudam a garantir a prática alinhada aos valores. Já o desafio de diferenciação entre cliente e beneficiário talvez seja aquele no qual a capacidade de apoio da certificação esteja menos notória. Pelo contrário, a heterogeneidade do grupo de empresas certificadas, sem a diferenciação entre as possibilidades de modelos de negócios, torna-se uma evidência da complexidade deste desafio.

Nesse sentido, os entrevistados referem-se às diferentes maneiras como uma organização pode incluir seu papel oficial, em consonância com abordagens que indicam os movimentos de hibridização como diferentes graus de hibridismo organizacional (Alter, 2007; Battilana et al., 2012; Schmitz, 2015). O desenvolvimento de uma definição clara e distinção entre impacto e performance socioambiental pela certificação poderia ser valioso para o campo, tanto acadêmico quanto da prática, dando mais sustentação aos argumentos da certificação.

Dessa maneira, apesar de o discurso oficial do movimento também levar ao entendimento do modelo ideal de hibridismo como negócio social (Battilana et al., 2012), a certificação atende a empresas com algum grau de hibridismo (Schmitz, 2015), ou seja, que já tenha incorporado práticas sociais de forma mais próxima ao centro da estratégia. Essa heterogeneidade das B Corps também é percebida em outros países, como em estudo semelhante realizado na Austrália, com a presença de empresas com alta integração entre as atividades sociais e comerciais e outras nas quais esta lógica está mais separada (Stubbs, 2015).

A certificação tal como está não permite, portanto, diferenciações do nível de integração entre a ação social e as atividades de mercado (Alter, 2006, 2007). Ao permitir uma amplitude maior do hibridismo organizacional, abre espaço para atrair mais empresas, porém, não diferencia aquelas orientadas à missão social e atuantes diretas na geração de valor socioambiental, o que seria mais

OS, Organizações e Sustentabilidade, 7(1), p. 47-70, Londrina, PR, jan./jun. 2019.

ISSN 2318-9223, http://www.uel.br/revistas/uel/index.php/ros/issue/view/1535/showToc 
aderente a uma visão latino-americana de negócios sociais, focados na inclusão (Comini, Barki, \& Aguiar, 2012; Márquez, Reficco, \& Berger, 2009).

A exigência de que seja uma empresa com fins lucrativos, mesmo que não distribua os dividendos demonstra a preponderância de visão e confirma a perspectiva conceitual de empreendimentos sociais norte-americana, alicerçada na visão da força empresarial como importante propulsor do desenvolvimento (Comini et al., 2012). Como o conceito de negócios sociais no país de origem do movimento é mais abrangente, essa influência é refletida também na abrangência dos argumentos e direcionamentos da certificação, incluindo toda a atividade empreendedora de mercado que exerça impacto social nas suas atividades de negócio. A preponderância de organizações privadas com lógica de mercado indica, portanto, concentração mais para o extremo da motivação para o lucro do espectro de hibridismo.

Uma vez que a certificação também não avalia ou interfere na orientação à missão do modelo de negócio (Alter, 2006, 2007), a proteção da missão acontece por meio do mecanismo legal como objeto-fim no contrato social, mas não na visão de missão dentro do escopo da gestão estratégica do modelo de negócios (Khalifa, 2012; Pearce, 1982) e de definição da proposta de valor social (Austin et al., 2012).

\section{CONSIDERAÇÕES FINAIS}

O objetivo do Movimento B Corp é ousado: buscar "redefinir o conceito de sucesso nos negócios". A necessidade de mensuração é um importante ponto de convergência entre o propósito do movimento B e o interesse prático das empresas certificadas. Nenhuma empresa B é perfeita, mas está disposta a ser cada vez melhor para o mundo. O processo de certificação é uma forma de perseguir essa intenção. Os motivadores constituem os gatilhos-chave de decisão para certificar: posicionamento ideológico, atração de investimento de impacto e manutenção da missão e cultura.

O networking e a reputação pessoal são os principais impulsionadores do movimento. Fazer parte de uma comunidade que partilha dos mesmos valores é um importante ponto positivo, reforçando achados anteriores (Stubbs, 2017) e levando a respostas e interpretações muito semelhantes no Brasil e nos Estados Unidos. Todavia, a mistura entre as pessoas e as empresas é um ponto de atenção, uma vez que a reputação dos fundadores e gestores aparece diretamente associada à empresa, mas não é garantia de que ela já reflete isso, até mesmo pelos grandes desafios de empreender e a complexidade das relações organizacionais. 0 envolvimento emocional e ideológico dos líderes também interfere nas percepções sobre o movimento e, até mesmo, na avaliação crítica. Uma visão mais criteriosa sobre essas diferenças é necessária para observar as potencialidades, fragilidades e desafios com mais acuracidade. Essa ênfase nas pessoas também o aproxima bastante, como discurso e como imagem, do Capitalismo Consciente, cujo pilar central está nas pessoas, seus valores, crenças e propósitos refletidos diretamente nas organizações (Mackey \& Sisodia, 2014).

Para que o diferencial de mensuração de impacto socioambiental seja seu principal alicerce, definir e distinguir performance, impacto e valor socioambiental na avaliação BIA é fundamental para construir maior sentido à certificação e fortalecer a consistência das mensagens-chave do movimento. Até mesmo durante as entrevistas não houve consenso sobre o tema e conteúdo da certificação, mas há uma visão clara de que a definição do que é o impacto deve ser esclarecida, a fim de diminuir o tom idealista do discurso e dar mais luz para os aspectos concretos da avaliação. Aparece também o risco da certificação ser um negócio e uma das fontes de renda para a sobrevivência do movimento. Em último nível, o movimento, representado pelo B-Lab e Sistema B, vive os mesmos desafios de uma organização híbrida, pois precisa equilibrar seu propósito de estimular empresas mais conscientes, mas garantir sua sustentabilidade financeira. Há o desafio de crescer, mas equilibrar o cuidado de não abrir exceções que possam descaracterizar o movimento.

OS, Organizações e Sustentabilidade, 7(1), p. 47-70, Londrina, PR, jan./jun. 2019.

ISSN 2318-9223, http://www.uel.br/revistas/uel/index.php/ros/issue/view/1535/showToc 
Como um dos estudos pioneiros no Brasil sobre o tema, esta pesquisa constitui uma base de conhecimento e entendimento sobre o movimento B. No campo teórico, contribui para o campo de organizações híbridas ao analisar as influências de abordagens que buscam abordar o papel socioambiental das organizações para a formação do conceito. Ainda é prematuro afirmar se, de fato, representa uma mudança significativa no propósito geral das organizações ou se trata de um movimento global expressivo e perene. A certificação de empresas B representa um avanço nos atuais mecanismos de mensuração e uma alternativa abrangente e unificada para avaliar e comparar impacto socioambiental, pois compreende diversos critérios já estabelecidos e os unifica em uma única avaliação. Os significados, potencialidades e desafios analisados reforçam a menção ao potencial do movimento B Corp em estimular novos modelos organizacionais (André, 2012; Battilana et al., 2012; Bilgili et al., 2015; Chen \& Kelly, 2015; Dufays \& Huybrechts, 2015; Haigh \& Hoffman, 2012). Assim como afirmam Waddock \& Mclntosh (2011), ainda não é possível afirmar se serão suficientes para a magnitude da mudança necessária. Ainda é uma pergunta aberta, mas que aponta caminhos para repensar o modelo de negócios, e da noção do que é valor.

\section{REFERÉNCIAS}

Aguinis, H., \& Glavas, a. (2012). What We Know and Don't Know About Corporate Social Responsibility: A Review and Research Agenda. Journal of Management, 38(4), 932-968. Recuperado de <http://doi.org/10.1177/0149206311436079>

Alter, S. K. (2006). Social Enterprise Models and Their Mission and Money Relationships. In A. Nicholls (Ed.), Social Entrepreneuriship: New Models of Sustainable Social Change (pp. 205-232). Oxford: Oxford University Press.

Alter, S. K. (2007). Social Enterprise Typology. Virtue Ventures LLC, 1-31. Recuperado de <http://rinovations.edublogs.org/files/2008/07/setypology.pdf>

André, R. (2012). Assessing the Accountability of the Benefit Corporation: Will This New Gray Sector Organization Enhance Corporate Social Responsibility? Journal of Business Ethics, 110(1), 133-150. Recuperado de <http://doi.org/10.1007/s10551-012-1254-1>

Angelo, F. D., Amui, L. B. L., Caldana, A. C. F., \& Jabbour, C. J. C. (2012). Towards a strategic CSR: a Brazilian case study. Business Strategy Series, 13(5), 224-238. Recuperado de: <http://doi.org/10.1108/17515631211264104>

Austin, J., Stevenson, H., \& Wei-Skillern, J. (2012). Social and commercial entrepreneurship: same, different, or both? Revista de Administração, 47(3), 370-384. http://doi.org/10.5700/rausp1055

B-Lab. (2015). B Corporation Website. Retrieved October 6, 2016, Recuperado de: $<$ www.bcorporation.net $>$.

Bakker, F. De, Groenewegen, P., \& Den Hond, F. (2005). A Bibliometric Analysis of 30 Years of Research and Theory on Corporate Social Responsibility and Corporate Social Performance. Business \& Society, 44(3), 283-317. Recuperado de <http://doi.org/10.1177/0007650305278086>

Bandeira-de-Mello, R., \& Cunha, C. (2003). Operacionalizando o método da Grounded Theory nas Pesquisas em Estratégia: Técnicas e Procedimentos de Análise com apoio do Software Atlas/TI. In Anais do Encontro de Estudos em Estratégias da Anpad (Vol. 1-18, p. 18). Curitiba: Anpad.

Barki, E., \& Aguiar, L. (2013). Negócios com Impacto Social em Grandes e Pequenas Empresas. In E. (org. . Barki (Ed.), Negócios com Impacto Social no Brasil (pp. 65-81). São Paulo -SP: Peirópolis.

Battilana, J., \& Dorado, S. (2010). Building Sustainable Hybrid Organizations: The Case of Commercial Microfinance Organizations. Academy of Management Journal, 53(6), 1419-1440. Recuperado de <http://doi.org/10.5465/AMJ.2010.57318391> 
Battilana, J., \& Lee, M. (2014). Advancing Research on Hybrid Organizing - Insights from the Study of Social Enterprises. The Academy of Management Annals, 8(1), 397-441. Recuperado de <http://doi.org/10.1080/19416520.2014.893615>

Battilana, J., Lee, M., Walker, J., \& Dorsey, C. (2012). In Search of the Hybrid Ideal. Stanford Social Innovation Review, 10(3), 49-55. Recuperado de <http://ssir.org/articles/entry/in_search_of_the_hybrid_ideal>

Berger, P. L., \& Luckmann, T. (1976). A construção social da realidade: tratado de sociologia do conhecimento (2nd ed.). Petrópolis: Vozes.

Bilgili, H., Worrell, D. L., Ellstrand, A. E., \& Johnson, J. L. (2015). Breaking the Mold of Traditional Business: The Emergence and Diffusion of B-Organizational Forms. In Academy of Management Proceedings. Vancouver: Academy of Management.

Blowfield, M., \& Murray, A. (2008). The meaning and the origins of corporate responsibility. In M. Blowfield \& A. Murray (Eds.), Corporate responsibility: a critical introduction (p. 425 p.). Oxford: Oxford University Press.

Boaventura, J. M. G., Silva, R. S. da, \& Bandeira-de-Mello, R. (2012). Performance Financeira Corporativa e Performance Social Corporativa: desenvolvimento metodológico e contribuição teórica dos estudos empíricos. Revista Contabilidade \& Finanças, 23(60), 232-245. Recuperado de <http://doi.org/10.1590/S1519-70772012000300008>

Brandão, D., Cruz, C., \& Arida, A. L. (2014). Métricas em negócios de impacto social: Fundamentos. São Paulo: ICE e MOVE. Retrieved from http://ice.org.br/metricas-em-negocios-de-impacto-socialfundamentos/

Brandsen, T., \& Karré, P. M. (2011). Hybrid Organizations: No Cause for Concern? International Journal of Public Administration, 34(13), 827-836. Recuperado de <http://doi.org/10.1080/01900692.2011.605090>

Cajazeira, J. E. R., \& Barbieri, J. C. (2009). Responsabilidade social empresarial e empresa sustentável: da teoria à prática. São Paulo: Saraiva.

Carroll, A. B. (1979). A Three-Dimensional Conceptual Model of Corporate Performance. Academy of Management Review, 4(4), 497-505. Recuperado de <http://doi.org/10.5465/AMR.1979.4498296>

Carroll, A. B. (1991). The pyramid of corporate social responsibility: Toward the moral management of organizational stakeholders. Business Horizons, 34(4), 39-48. Recuperado de <http://doi.org/10.1016/0007-6813(91)90005-G>

Carroll, A. B. (1999). Corporate Social Responsibility: Evolution of a Definitional Construct. Business \& Society, 38(3), 268-295. Recuperado de <http://doi.org/10.1177/000765039903800303>

Chen, X., \& Kelly, T. F. (2015). B-Corps - A Growing Form of Social Enterprise: Tracing Their Progress and Assessing Their Performance. Journal of Leadership \& Organizational Studies, 22(1), 102-114. Recuperado de <http://doi.org/10.1177/1548051814532529>

Clarkson, M. E. (1995). A stakeholder framework for analyzing and evaluating corporate social performance. Academy of Management Review, 20(1), 92-117. Recuperado de <http://doi.org/10.5465/AMR.1995.9503271994>

Comini, G., Barki, E., \& Aguiar, L. T. De. (2012). A three-pronged approach to social business: a Brazilian multi-case analysis social businesses. Revista de Administração, 47(3), 385-397. Recuperado de <http://doi.org/10.5700/rausp1045> 
Crane, A., Palazzo, G., Spence, L. J., \& Matten, D. (2014). Contesting the Value of "Creating Shared Value". California Management Review, 56(2), 130-153.

Dahlsrud, A. (2008). How corporate social responsibility is defined: An analysis of 37 definitions. Corporate Social Responsibility and Environmental Management, 15(1), 1-13. Recuperado de <http://doi.org/10.1002/csr.132>

Dembek, K., Singh, P., \& Bhakoo, V. (2016). Literature Review of Shared Value: A Theoretical Concept or a Management Buzzword? Journal of Business Ethics, 137(2), 231-267. Recuperado de <http://doi.org/10.1007/s10551-015-2554-z>

Doherty, B., Haugh, H., \& Lyon, F. (2014). Social Enterprises as Hybrid Organizations: A Review and Research Agenda. International Journal of Management Reviews, 16(4), 417-436. Recuperado de <http://doi.org/10.1111/ijmr.12028>

Donaldson, T., \& Preston, L. (1995). The stakeholder theory of the corporation: Concepts, evidence, and implications. Academy of Management Review, 20(1), 65-91. Recuperado de <http://www.jstor.org/stable/258887>

Dufays, F., \& Huybrechts, B. (2015). Where do hybrids come from? Entrepreneurial team heterogeneity as an avenue for the emergence of hybrid organizations. International Small Business Journal, 1-20. Recuperado de <http://doi.org/10.1177/0266242615585152>

Ebrahim, A., Battilana, J., \& Mair, J. (2014). The governance of social enterprises: Mission drift and accountability challenges in hybrid organizations. Research in Organizational Behavior, 34, 81-100. Recuperado de <http://doi.org/10.1016/j.riob.2014.09.001>

Elkington, J. (2001). Canibais de Garfo e Face. São Paulo: Makron Books.

Fischer, R. M. (2002). Responsabilidade social: um conceito em busca de definição. In R. M. Fischer (Ed.), O Desafio da Colaboração: práicas de responsabilidade social entre empresas e terceiro setor (pp. 73-100). São Paulo: Editora Gente.

Fischer, R. M. (2014). Negocios Sociais. In R. de F. Boullosa (Ed.), Dicionário para a Formação em Gestão Social (pp. 125-127). Salvador - BA: CIAGS/UFBA.

Fischer, R. M., \& Comini, G. M. (2012). Sustainable development: from responsibility to entrepreneurship. Revista de Administração, 47(3), 363-369. Recuperado de <http://doi.org/10.5700/rausp1044>

Freeman, R. E. (1984). Strategic Management: A Stakeholder Approach. Boston: Pitman.

Freeman, R. E., Harrison, J., \& Wicks, A. (2007). Managing for stakeholders: survival, reputation, and success (1.). New Haven \& London: Yale University Press.

Gephart, R. (1999). Paradigms and Research Methods. Researh Methods Forum, 4(Summer 1999), $1-11$.

Gonçalves-Dias, S. L. F. (2014). Sustentabilidade. In R. de Freitas (Ed.), Dicionário para a Formação em Gestão Social (1st ed., pp. 165-168). Salvador: CIACS/UFBA.

Conçalves-Dias, S. L. F., Teodósio, A. dos S. de S., \& Barbieri, J. C. (2007). Desafios e perspectivas da sustentabilidade: caminhos e descaminhos na gestão empresarial. In IX Engema (pp. 1-16). Recuperado de <http://engema.up.edu.br/arquivos/engema/pdf/PAP0289.pdf>

Griffin, J. J. (2000). Corporate Social Performance: Research Directions for the 21st Century. Business \& Society, 39(4), 479-491. Recuperado de <http://doi.org/10.1177/000765030003900407> 
Haigh, N., \& Hoffman, A. J. (2012). Hybrid organizations: The next chapter of sustainable business.

Organizational Dynamics, 41(2), 126-134. Recuperado de <http://doi.org/10.1016/j.orgdyn.2012.01.006>

Haigh, N., \& Hoffman, a. J. (2014). The New Heretics: Hybrid Organizations and the Challenges They Present to Corporate Sustainability. Organization \& Environment, 27(3), 223-241. Recuperado de <http://doi.org/10.1177/1086026614545345>

Haigh, N., Walker, J., Bacq, S., \& Kickul, J. (2015). Hybrid organizations; Origins, Strategies and Implications. California Management Review, 57(3), 5-12.

Harrison, J. S., Bosse, D. A., \& Phillips, R. A. (2010). Managing for stakeholders, stakeholder utility functions, and competitive advantage. Strategic Management Journal, 31(1), 58-74. Recuperado de <http://doi.org/10.1002/smj.801>

Izzo, D. (2013). Fontes de Financiamento. In E. Barki (Ed.), Negócios com Impacto Social no Brasil (pp. 150-169). São Paulo: Peirópolis.

Kaiserfeld, T. (2013). Why New Hybrid Organizations are Formed: Historical Perspectives on Epistemic and Academic Drift. Minerva, 51(2), 171-194. Recuperado de <http://doi.org/10.1007/s11024-013-9226-x>

Khalifa, A. S. (2012). Mission, purpose, and ambition: redefining the mission statement. Journal of Strategy and Management, 5(3), 236-251. Recuperado de <http://doi.org/10.1108/17554251211247553>

Langley, A. (1999). Strategies for theorizing from process data. Academy of Management Review, 24(4), 691-710. Recuperado de <http://doi.org/10.5465/AMR.1999.2553248>

Langrafe, T. de F., \& Oliveira, A. C. B. (2014). Como mensurar a Corporate Social Performance? 0 Estado da Arte. In XVII SemeAd Seminários em Administração. São Paulo: FEA-USP. Recuperado de <http://sistema.semead.com.br/17semead/resultado/an_resumo.asp?cod_trabalho=1164>

Lantos, G. P. (2001). The boundaries of strategic corporate social responsibility. Journal of Consumer Marketing, 18(7), 595-632. Recuperado de <http://doi.org/10.1108/07363760110410281>

Lee, M., \& Battilana, J. (2013). How the Zebra Cot its Stripes: Imprinting of Individuals and Hybrid Social Ventures (Harvard Business School Organizational Behavior Unit Working Paper). Harvard Business School Organizational Behavior Unit Working Paper (Vol. 14-5). Business School Organizational Behavior Unit Working Paper. Recuperado de <http://www.hbs.edu/faculty/PublicationFiles/14-005_3b5dfa9a-58ec-4279-83fa9305a93883d8.pdf>

Mackey, J., \& Sisodia, R. (2014). Capitalismo Consciente. São Paulo: HSM Editora.

Márquez, P., Reficco, E., \& Berger, G. (2009). Negocios Inclusivos en America Latina. Harvard Business Review, 87(5), 28-38.

Mitchell, R. K., Agle, B. R., \& Wood, D. J. (1997). Toward a theory of stakeholder identification and salience: Defining the principle of who and what really counts. Academy of Management Review, 22(4), 853-886. Recuperado de <http://doi.org/10.5465/AMR.1997.9711022105>

Mohan, A. (2003). Strategies for the management of complex practices in complex organizations: A study of the transnational management of corporate responsibility. University of Warwick, United Kingdom.

Oliveira Filho, G. R., Kiyama, R. S., \& Comini, G. M. (2013). Os Desafios de Mensurar o Impacto Social. In E. Barki (Ed.), Negócios com Impacto Social no Brasil (pp. 211-235). São Paulo: Peirópolis. 
Pearce, J. (1982). The company mission as a strategic tool. Sloan Management Review, 23(3), 15-24. Pettigrew, A. M. (1985). Contextualist research: A natural way to link theory and practice. In E. E. Lawler, A. M. Mohrman, S. A. Mohrman, G. E. Ledford Jr., \& T. G. Cummings (Eds.), Doing Research That Is Useful for Theory and Practice (pp. 222-248). San Francisco: Jossey-Bass.

Pfitzer, M., Bockstette, V., \& Stamp, M. (2013). Innovating for shared value. Harvard Business Review, 91(9).

Porter, M. E., \& Kramer, M. R. (2006). Strategy and society: the link between competitive advantage and corporate social responsibility. Harvard Business Review, 84(12), 78-92. Recuperado de <https://hbr.org/2006/12/strategy-and-society-the-link-between-competitive-advantage-andcorporate-social-responsibility>

Porter, M. E., \& Kramer, M. R. (2011). Creating Shared Value. Harvard Business Review, 89(1/2), 6277. Recuperado de <https://hbr.org/2011/01/the-big-idea-creating-shared-value>

Ramachandran, V. (2011). Strategic corporate social responsibility: a "dynamic capabilities" perspective. Corporate Social Responsibility and Environmental Management, 18(5), 285-293. Recuperado de <http://doi.org/10.1002/csr.251>

Reiser, D. B. (2010). Governing and financing blended enterprise. Chicago-Kent Law Review, 85(2), 619-655. Recuperado de <http://scholarship.kentlaw.iit.edu/cklawreview/vol85/iss2/6>

Sabeti, H. (2011). To Reform Capitalism, CEOs Should Champion Structural Reforms. Harvard Business Review, October 18. Recuperado de <https://hbr.org/2011/10/to-reform-capitalism-ceosshou>

Santos, F., Pache, A.-C., \& Birkholz, C. (2015). Making Hybrids Work: Aligning Business Models and Organizational Design for Social Enterprises. California Management Review, 57(3), 36-58. Recuperado de <http://doi.org/10.1525/cmr.2015.57.3.36>

Schmitz, B. (2015). Beyond Structural Governance. International Studies of Management $\&$ Organization, 45(3), 241-258. Recuperado de <http://doi.org/10.1080/00208825.2015.1006029>

Schoolman, E. D., Guest, J. S., Bush, K. F., \& Bell, A. R. (2012). How interdisciplinary is sustainability research? Analyzing the structure of an emerging scientific field. Sustainability Science, 7(1), 67-80. Recuperado de <http://doi.org/10.1007/s11625-011-0139-z>

Schröer, A., \& Jäger, U. (2015). Beyond Balancing? International Studies of Management \& Organization, 45(3), 259-281. Recuperado de <http://doi.org/10.1080/00208825.2015.1006032>

Sistema B. (2014). Sistema B Website. Retrieved May 29, 2016, Recuperado de <www.sistemab.org> Stead, J. G., \& Stead, E. (2000). Eco-enterprise strategy: standing for sustainability. Journal of Business Ethics, 24(4), 313-329. Recuperado de <http://doi.org/10.1023/A:1006188725928>

Strauss, A., \& Corbin, J. (2008). Pesquisa Qualitativa: técnicas e procedimentos para o desenvolvimento de teoria fundamentada (2. ed.). Porto Alegre: Artmed.

Stubbs, W. (2015). Blending Institutional Logics: The Emergence of B Corps in Australia. In Academy of Management Proceedings (Vol. 2015, pp. 1-38). Vancouver: AOM. Recuperado de <http://doi.org/10.5465/AMBPP.2015.10254abstract>

Stubbs, W. (2017). Characterising B Corps as a sustainable business model: An exploratory study of B Corps in Australia. Journal of Cleaner Production, (July). Recuperado de <http://doi.org/10.1016/j.jclepro.2016.12.093>

Veiga, J. E. da. (2013). Desenvolvimento Sustentável. São Paulo: Garamond. 
Waddock, S., \& McIntosh, M. (2011). Business Unusual: Corporate Responsibility in a 2.0 World*. Business and Society Review, 116(3), 303-330. Recuperado de <http://doi.org/10.1111/j.14678594.2011.00387.x>

Wilburn, K., \& Wilburn, R. (2014). The double bottom line: Profit and social benefit. Business Horizons, 57(1), 11-20. Recuperado de <http://doi.org/10.1016/j.bushor.2013.10.001>

Wood, D. (2010). Measuring Corporate Social Performance: A Review. International Journal of Management Reviews, 12(1), 50-84. Recuperado de <http://doi.org/10.1111/j.14682370.2009.00274.x>

Wood, D. J. (1991). Corporate Social Performance Revisited. Academy of Management Review, 16(4), 691-718. Recuperado de <http://doi.org/10.5465/AMR.1991.4279616>

Yaziji, M. (2008). Time to rethink capitalism? Harvard Business Review, 86(November), 1-24. Recuperado de <https://hbr.org/2008/11/time-to-rethink-capitalism> 